\title{
Coagulation Abnormalities in Patients with Cirrhosis in A Tertiary Hospital Sangli : A prospective Study
}

\author{
Sheetal Mahesh Sale ${ }^{1}$, Vaibhav Pandurang Mane ${ }^{1 *}$, Vishrabdha Rahul Pawar ${ }^{1}$, Dajiram G .Mote ${ }^{2}$, \\ Sushant Narayan Mohiteand ${ }^{1}$ and Vanisha Dhaka ${ }^{1}$ \\ Department of Pathology, Bharati Vidyapeeth Deemed University Medical College And Hospital, Sangli. India \\ Department of Surgery, Bharati Vidyapeeth Deemed University Medical College And Hospital, Sangli, India
}

\section{ABSTRACT}

Background: Clotting is a multistep process comprised of sequence of events of platelet plug formation, clotting process , clotting process termination and clot removal.Synthesis of clotting factors and clearance of their activation products took place in liver. The magnitude of clinical features and coagulation abnormalities will vary depending on liver dysfunction . Therefore wide spectrum of abnormalities were seen in patients of liver cirrhosis.

Aims and Objectives: To study the various coagulation abnormalities in patients of liver cirrhosis.

Methodology: This 1 year prospective study was conducted in a tertiary hospital for the evaluation of the frequency of coagulation abnormalities in patients with cirrhosis of liver. 82 patients presenting with cirrhosis of liver were selected and were evaluated for coagulation profile. The data was collected via questionnaire form and analyzed by SPSS (Statistical Packages for Social Sciences) version. Patients blood was tested for coagulation abnormalities including prothrombin time (PT), activated partial thromboplastin time (aPTT) and platelet count. In this study design control group of normal people without cirrhosis was not considered.

Results: In the present study, out of 82 , fifty $(60.9 \%)$ were males and thirty two (39.1) \% were females. According to Child's Pughs classification, 37(45.12\%) cirrhotic patients were in class A, $13(15.85 \%)$ in class B and $32(39.02 \%)$ in class C. The PT was prolonged $($ mean $+\mathrm{SD}=20.67 \pm 4.12 \mathrm{sec})$ in $44(53.65 \%)$ patients, while38 $(46.34 \%)$ patients had normal PT which was less than 14 seconds (mean $+\mathrm{SD}=12.13 \pm 1.01 \mathrm{sec})$. Activated partial thromboplastin time was prolonged in47 $(57.31 \%)$ patients, while 35 (42.68 \%) patients had normal APTT which was less than 40 seconds (mean $+\mathrm{SD}=33.05 \pm 3.06 \mathrm{sec}$ ). PT and APTT were significantly raised in cirrhotic patients.

Approximately 39\% CLD cases had decreased platelet count. Relative risk of GI bleeding with abnormal clotting tests in CLD cases were weakly positive for PT $(\mathrm{RR}=1.02 ; 95 \% \mathrm{CI}, 0.49-2.10)$, negative for aPTT ( $\mathrm{RR}=0.83 ; 95 \% \mathrm{CI}, 0.47-1.45)$, strongly positive for decreased platelet counts $(\mathrm{RR}=1.96 ; 95 \% \mathrm{CI}, 1.08-3.56)$.

Conclusion: Coagulation abnormalities are commonly seen in cirrhotic liver disease.Decreased platelet count and increased PT and APTT are commonly seen in chronic liver disease. These parameters can be used as prognostic markers.

Keywords: Cirrhosis, Prothromobin, Clotting, Coagulation Abnormalities, Chronic Liver Disease,

\section{Introduction}

The liver plays a central role in the clotting process. Acute and chronic liver diseases are invariably associated with coagulation disorders due to multiple causes including: decreased synthesis of clotting and inhibitor factors, decreased clearance of activated factors, quantitative and qualitative platelet defects, hyperfibrinolysis, and accelerated intravascular coagulation. ${ }^{[1,2,3,4,5]}$

Most coagulation factors are produced in liver, but the response of each factor to liver disease is variable due to differences in biologic half lives and acute phase reactions $[5,6]$ The PT is usually prolonged first, then APTT. Factor VII: shortest biologic half life, often affected earliest with largest decrease in plasma level. Factor VII also decreases earliest with warfarin treatment. Factor VIII: may be normal or elevated due to acute phase reactants. Factors XI and XII:have long biologic half lives, and may be normal until liver disease is advanced. ${ }^{[7,8,]}$

However the D-Dimer is usually normal which is helpful to differentiate liver disease from DIC.[9,10,] The bleeding tendency accounts for increased risk of morbidity and mortality in patients with liver disease undergoing diagnostic or therapeutic invasive procedures

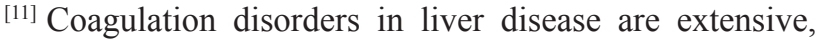
complex and expensive to treat. Many mechanisms can cause the coagulation changes, but many can be attributed to cytokine activation. Sepsis further impairs hemostasis in patients with liver cirrhosis bleeding from esophageal 
varices. Thrombotic events, even if rare in cirrhotic patients, can occur $\left.{ }^{[12,13}\right]$

In liver disease the platelet count is either normal or decreased. The liver is a source of thrombopoietin which stimulates platelet production. Mild splenomegaly may be present in cirrhosis resulting in platelet pooling. Alcohol intake inhibits the production of platelets by megakaryocytes. Folate deficiency, which may accompany cirrhosis may also cause thrombocytopenia. ${ }^{[14]}$

The prolonged PT is related to the severity of liver failure and is one of the parameter used in commonly used prognostic indices of chronic liver disease such as ChildPugh or Mayo End-Stage Liver Disease (MELD) scores. ${ }^{[6,7]}$ The PT is considered as a simple, inexpensive, qualitative and accurate prognostic marker of liver impairment and also a predictor of bleeding ${ }^{[1]}$ The degree of PT impairment an expression of decreased liver synthesis predicts the severity of portal hypertension and the presence of esophageal varices ${ }^{[6]} \mathrm{PT}$ is related both to bleeding risk and mortality. Patients with moderately or severely prolonged PT have 5 to 10 fold higher mortality rates than patients with normal $\mathrm{PT}^{[8]}$ The aPTT is also prolonged in advance chronic liver disease ${ }^{[9,16,17]}$

To study the alteration in coagulation profile in cirrhotic liver diseases which helps to evaluate the risk of bleeding in patients with liver disease and to study the association of coagulation abnormality with the extent of liver disease.

\section{Materials and Methods}

This one year prospective study was conducted at a tertiary hospital .Confirmed cases of cirrhosis (by clinical, biochemical, radiological and prior biopsy if done as described earlier) were selected, both sexes with age $>14$ years (to exclude pediatric age group). The exclusion criteria of the study were, patients of cirrhosis with a previous history of coagulation disorders and drug intake that causes changes in the coagulation parameters e.g. Oral
Contraceptive, aspirin, heparin, warfarin, etc, pregnant ladies and other liver disease patterns (non-cirrhotic liver disorders). All cirrhotic patients admitted t, that meets the inclusion and exclusion criteria were enrolled in this study. At first an adequate history was taken regarding hematemesis, melena, hemoptysis and hematuria, the presence of petechial hemorrhages or bruises. A focused clinical examination was done regarding the presence of petechial hemorrhages, bruises, the presence of ascites, the grade of hepatic encephalopathy (according to West Haven System) and per rectal examination was done to assess the presence of melena. The clinical examination was focus on bleeding tendencies and the clinical parameters of Child Pugh Class of severity of cirrhosis of liver. Secondly blood tests were done for platelet count, PT and APTT. All the data was collected on predesign proforma and statistical package for social sciences (SPSS) version 16 was used for data processing purpose. Frequencies and means \pm Standard Deviation of data like age PT and APTT was calculated. All values considered significant when $\mathrm{p}$ value is 0.05 .

Blood samples from the patients were collected and following three coagulation tests were performed. 1) PT. 2) APTT 3) Platelet count. Staging of chronic liver diseases is done by modified Child-Pugh classification with a scoring system of 5- 15. The Child-Pugh score is calculated by adding the scores of the five factors and can range from 5-15. (table-I)

Recently the model for end stage liver disease (MELD) score is used for assessing the need for liver transplantation.

MELD score $=9.57 \times \log { }_{\mathrm{e}}$ creatinine $(\mathrm{mg} / \mathrm{dl})+3.78 \times \log$ bilirubin(mg/dl)+11.20xlog e International normalized ratio(INR)+6.43

A comprehensive history including presenting complaints, past history, family history, drug history was taken by asking questions through a structured questionnaire. Thorough, physical examination was performed and

Table 1: Child - Pugh classification of cirrhosis

\begin{tabular}{|c|c|c|c|c|}
\hline Factors & Units & 1 & 2 & 3 \\
\hline Sr.Bilirubin & $\mathrm{Mg} / \mathrm{dl}$ & $<2.0$ & 2.0 to 3.0 & $>3.0$ \\
\hline Sr.Albumin & $\mathrm{g} / \mathrm{dl}$ & $>3.5$ & 3.0 to 3.5 & $<3.0$ \\
\hline \multirow[t]{2}{*}{ Prothrombin time } & Seconds prolonged & 4 & 4- 6 & $>6$ \\
\hline & International normalized ratio (INR) & $<1.7$ & $1.7-2.3$ & $>2.3$ \\
\hline Ascites & & None & Easily controlled & Poorly controlled \\
\hline Hepatic encephalopathy & & None & Minimal & Advanced \\
\hline
\end{tabular}

StageA-score5-6. Stage B-score7-9. Stage C-score10 or more. 
clinically CLD suspected patients were investigated for the confirmation of chronic liver disease through Liver Function Test (LFT) and ultrasound abdomen. The criteria used for the diagnosis of CLD were based on:

Presence of cardinal signs and symptoms including ascites, hepatomegaly, splenomegaly, jaundice, palmar erythema, clubbing, leukonychia, oedema, pubic hair loss, spider naevi, purpura, gynaecomastia, flapping tremors, drowsiness and coma. Ultrasonoghaphy revealing coarse hepatic texture, change in liver size, dilated portal vein and splenomegaly.

\section{Results}

This one year study was carried out in a tertiary hospital .82 patients presenting with cirrhosis of liver were selected for the analysis of coagulation profile.

In the present study, out of 82 , fifty $(60.9 \%)$ were males and 32 (39.1) \% were females. According to Child's Pughs classification,37(45.12\% ) cirrhotic patients were in class
A, $13(15.85 \%)$ in class B and $32(39.02 \%)$ in class C. The PT was prolonged (mean $+\mathrm{SD}=20.67 \pm 4.12 \mathrm{sec}$ ) in $44(53.65 \%)$ patients, while38 $(46.34 \%)$ patients had normal PT which was less than 14 seconds (mean + SD $=12.13 \pm 1.01 \mathrm{sec})$. Activated partial thromboplastin time was prolonged in47 (57.31\%) patients, while35 (42.68 $\%$ ) patients had normal APTT which was less than 40 seconds (mean $+\mathrm{SD}=33.05 \pm 3.06 \mathrm{sec}$ ). PT and APTT were significantly raised in cirrhotic patients.

Approximately 39\% CLD cases had decreased platelet count. Relative risk of GI bleeding with abnormal clotting tests in CLD cases were weakly positive for PT $(\mathrm{RR}=1.02$; $95 \% \mathrm{CI}, 0.49-2.10)$, negative for aPTT $(\mathrm{RR}=0.83 ; 95 \% \mathrm{CI}$, $0.47-1.45)$, strongly positive for decreased platelet counts $(\mathrm{RR}=1.96 ; 95 \% \mathrm{CI}, 1.08-3.56)$.

Bleeding was present in 21 out of 32 cases in which platelet count was altered and 10 out of 50 cases in which platelet count was normal

Table 2: Cirrhotic patients in relation to prothrombin time.

\begin{tabular}{|l|c|c|}
\hline $\begin{array}{l}\text { Prothrombin time } \\
\text { (Normal range: 12-14 sec) }\end{array}$ & Frequency & \% \\
\hline Normal & 40 & 48.4 \\
\hline Prolonged & 42 & 50.82 \\
\hline-3 & 15 & 18.15 \\
\hline $4-5$ & 19 & 22.99 \\
\hline+6 & 08 & 9.68 \\
\hline Total & $\mathbf{8 2}$ & $\mathbf{1 0 0}$ \\
\hline
\end{tabular}

P-value: 0.001 (Significant)

Table 3: Cirrhotic patients in relation to activated partial thromboplastin time.

\begin{tabular}{|l|c|c|}
\hline $\begin{array}{l}\text { Activated partial thromboplsatin time } \\
\text { (Normal range: } \mathbf{3 0 - 4 0 s e c )}\end{array}$ & Frequency & $\%$ \\
\hline Normal & 39 & 47.19 \\
\hline Prolonged & 43 & 52.03 \\
\hline Total & $\mathbf{8 2}$ & $\mathbf{1 0 0}$ \\
\hline
\end{tabular}

$P$-value $=0.001$ (Significant)

Table 4: Cirrhotic patients in relation platelet count.

\begin{tabular}{|l|c|c|}
\hline Platelet count $/ \mathrm{cmm}$ & No. of patients & Percentage \\
\hline Normal & 50 & 60.5 \\
\hline 50000 to 1 lakh & 21 & 25.41 \\
\hline Less than 50,000 & 11 & 13.31 \\
\hline Total & $\mathbf{8 2}$ & $\mathbf{1 0 0}$ \\
\hline
\end{tabular}

Table 5 . Distribution of cases according to Child-Pugh class in cirrhosis

\begin{tabular}{|l|c|c|}
\hline Child - Pugh Class & Number of cases & Percentage of cases \\
\hline Class A & 37 & $45.12 \%$ \\
\hline Class B & 13 & $15.85 \%$ \\
\hline Class C & 32 & $39.02 \%$ \\
\hline Total & $\mathbf{8 2}$ & $\mathbf{1 0 0 . 0 0}$ \\
\hline
\end{tabular}


Table 6. Comparison of percentage of cases with altered coagulation profile in cirrhosis with previous studies

\begin{tabular}{|l|c|c|c|}
\hline \multirow{2}{*}{ Studies } & \multicolumn{2}{|c|}{ Percentage of cases with altered coagulation profile } \\
\cline { 2 - 4 } & Altered PT & Altered APTT & Altered Platelet \\
\hline Siddiqui et al & $87.7 \%$ & $71.3 \%$ & 36.8 \\
\hline Nwokediuko et al & $36.6 \%$ & $22.6 \%$ & $42.7 \%$ \\
\hline Nieuwenhuizen et al & $79 \%$ & $42 \%$ & $11 \%$ \\
\hline Devrajani et al & $50.85 \%$ & $51.7 \%$ & - \\
\hline Present Study & $50.82 \%$ & $52.03 \%$ & $39 \%$ \\
\hline
\end{tabular}

\section{Discussion}

The clotting is a multistep process comprised of sequence of events of platelet plug formation, clotting process, clotting process termination and clot removal .Synthesis of clotting factors and clearance of their activation products took place in liver. The magnitude of clinical features and coagulation abnormalities will vary depending on liver dysfunction. Therefore wide spectrum of abnormalities will be seen in patients of liver cirrhosis

This study revealed that males suffer slightly more with chronic liver disease than females (male/female ratio was 1.56:1), more so, in the age group between $50-70$ years

Prolong PT has been associated with an increased risk of gastrointestinal bleeding in chronic liver disease ${ }^{[17,19]}$ This, study reported that majority of CLD patients had raised PT) and presented with GI bleeding .Although relative risk of GI bleeding with elevated PT was not statistically significant. Elevated aPTT was also not found to be associated with GI bleeding in this study. Possible explanation for this result may be because of their limitation, PT and aPTT only measure procoagulants factors, they do not measure anticoagulants factors (protein $\mathrm{C}$ and antithrombin) and the normal haemostasis is the strict balance between procoagulant and anticoagulant factors. ${ }^{[3]}$ Other likely causes of prolonged PT are oral anticoagulation, vitamin $\mathrm{K}$ deficiency and for prolonged aPTT are heparin contamination and non-specific inhibitors (lupus coagulants). ${ }^{[5]}$ Nevertheless, these parameters do give a good estimate of the synthetic function of the liver and may still be used as a prognostic marker ${ }^{[6,7]}$

Bleeding is a frequent and often severe complication of liver cirrhosis. The most frequent and potentially lifethreatening site is the gastrointestinal tract. Haemodynamic alterations secondary to portal hypertension are considered the main cause of GI bleeding in cirrhotics: ${ }^{[2,21]}$ Nonhaematological factors may also contribute to the bleeding diathesis in chronic liver disease. These include portal hypertension, renal failure and bacterial infection. ${ }^{[22]}$
In liver disease the platelet count is either normal or decreased. The liver is a source of thrombopoietin which stimulates platelet production. Mild splenomegaly may be present in cirrhosis resulting in platelet pooling. Alcohol intake inhibits the production of platelets by megakaryocytes. Folate deficiency, which may accompany cirrhosis may also cause thrombocytopenia.

The bleeding tendency accounts for increased risk of morbidity and mortality in patients with liver disease undergoing diagnostic or therapeutic invasive procedures. Coagulation disorders in liver disease are extensive, complex and expensive to treat. Many mechanisms can cause the coagulation changes, but many can be attributed to cytokine activation. Sepsis further impairs hemostasis in patients with liver cirrhosis bleeding from esophageal varices. Thrombotic events, even if rare in cirrhotic patients, occur mainly in the portal and mesenteric veins.

Liver Disease is a complex disorder that impacts coagulation testing. It must be diagnosed cost effectively and treated appropriately.

\section{Conclusion}

The study is concluded with the fact that the coagulation profile was significantly altered in cases of cirrhosis. The alteration of coagulation profile was not significant in cases of hepatitis and other liver diseases. The risk of bleeding was more in the cases of cirrhosis with altered

coagulation profile.Coagulation abnormalities were significantly associated with the extent of liver disease.By earlier identification of patients at risk of bleeding, early treatment can be started.

\section{Acknowledgement}

The authors are thankful to the Department of Medicine, Technicial Staff, BVDUMC \& H, Sangli, for their help and cooperation

\section{References}

1. Amitrano L, Guardascione MA, Brancaccio V, Balzano A. Coagulation disorders in liver disease. Semin Liver Dis 2002; 22: 83-96. 
2. Peck Radosavljevic M. Review article: coagulation disorders in chronic liver disease. Aliment Pharmacol Ther 2007; 26 Suppl 1: 21-8.

3. Rverter JC. Abnormal hemostasis tests and bleeding in chronic liver disease: are they related? Yes. J Thromb heamost 2006; 4: 717-20.

4. Tripodi A. Tests of coagulation in liver disease. Clin Liver Dis 2009; 13: 55-61.

5. Thachil J. Relevance of clotting tests in liver disease. Postgrad Med J 2008; 84: 177-81.

6. Pugh RN, Murray-Lyon IM, Dawson JL, Pietroni MC, Williams R. Transection of the oesophagus for bleeding oesophageal varices. Br J Surg 1973; 60: 649-9.

7. Formen LM, Lucey MR. Predicting the prognosis of chronic liver disease: an evolution from child to MELD. Mayo endstage liver disease. Hepatology 2001; 33: 473-5.

8. Garrison RN, Cryer HM, Howard DA, Polk HC. Clarification of risk factor for abdominal operations in patients with hepatic cirrhosis. Ann Surg 1984; 199: 648-55.

9. Hedner U, Erhardtsen E. Hemostatic disorders in liver disease. In: Schiff ER, Sorrell MF, Maddrey WC, editors. Diseases of the liver. Philadelphia: Lippincott Williams and Wilkins; 2003; pp 625-35.

10. Lechner K, Niessner H, Thaler E. Coagulation abnormalities in liver disease. Semin Thromb Hemost 1977; 4: 40-56.

11. Bashour FN, Teran JC, Mullen KD. Prevalence of peripheral blood cytopenias (hypersplenism) in patients with nonalcoholic chronic liver disease. Am J Gastroenterol 2000; 95: 2936-9.

12. Schepis F, Camma C, Niceforo D, Magnano A, Pallio S, Cinquegrani $\mathrm{M}$, et al. Which patients with cirrhotic should undergo endoscopic screening for esophageal varices detection? Hepatology 2001; 33: 333-8.

13. Zaman A, Hapke R, Flora K, Rosen HR, Benner K. Factors predicting the presence of esophageal or gastric varices in patients with advanced liver disease. Am J Gastroenterol 1999; 94: 3292-6.
14. Clinical and Laboratory Standards Institute (CLSI). Collection, transport and processing of blood specimens for testing plasma-based coagulation assays and molecular hemostasis assays; approved guideline. 5th ed.H21-A5. Pennsylvania USA; 2008.

15. Clinical and Laboratory Standards Institute (CLSI). Procedure for the Determination of Fibrinogen in Plasma; Approved Guideline.2nd ed.H30-A2.Pennsylvania, USA; 2001.

16. Bukhtiari N, Hussain T, Iqbal M, Malik AM, Qureshi AH, Hussain A. Hepatits B and C single and co-infection in Chronic liver disease and their effect on the disease pattern. J Pak Med Assoc 2003; 53: 136-40.

17. Nidegger D, Ragot S, Berthelemy P, Masliah C, Pilette C, Martin T, et al. Cirrhosis and bleeding: the need for very earlymanagement. J Hepatol 2003; 39: 509-14.

18. Patch D, Armonis A, Sabin C, Christopoulou K, Greenslade L, McCormick A, et al. Single portal pressure measurement predicts survival in cirrhotic patients with recent bleeding. Gut 1999; 44: 264-9.

19. Lecleire S, Di Fiore F, Merle V, Herve S, Duhamel C, Rudelli A, et al. Acute upper gastrointestinal bleeding in patients with liver cirrhosis and in noncirrhotic patients: epidemiology and predictive factors of mortality in a prospective multicenter population-based study. J Clin Gastroenterol 2005; 39: 321-7.

20. Escorsell A, Bordas JM, Castaneda B, Liach J, Garcia-Pagan $\mathrm{JC}$, Rodes J, et al. Predictive value of the variceal pressure response to continued pharmacological therapy in patients with cirrhosis and portal hypertension. Hepatology 2000; 31: 1061-7.

21. Dell'era A, Bosch J. Review article: the relevance of portal pressure and other risk factors in acute gastro-oesophageal variceal bleeding. Aliment Pharmacol Ther 2004; 20 Suppl 3: 8-15.

22. Lisman T, Bongers $\mathrm{T}$, Adelmeijer J, Janssen $\mathrm{H}$, de Maat M, de Groot P, et al. Elevated levels of von Willebrand factor in cirrhosis support platelet adhesion despite reduced functional capacity. Hepatology 2006; 44: 53-61.

*Corresponding author:

Dr. Vaibhav Pandurang Mane, Flat No. 1 Shri Ramshailya Apartment, Neminath nagar, Vishrambag, Sangli. India

Phone: +91 9422041490

Email: vaishnavilab1060@gmail.com

Date of Submission : 31.01.2017

Date of Acceptance : 17.02.2017

Financial or other Competing Interests: None.

Date of Publication : 15.06.2017 